\title{
Khat use and neurobehavioral functions: Suggestions for future studies
}

\author{
Richard Hoffman*, Mustafa Al'Absi \\ Department of Behavioral Sciences, University of Minnesota Medical School Duluth, 1035 University Avenue, Duluth, MN 55812-3031, USA
}

\section{A R T I C L E I N F O}

\section{Article history:}

Received 3 September 2009

Received in revised form 5 March 2010

Accepted 16 May 2010

Available online 27 May 2010

\section{Keywords:}

Khat

Cathinone

Amphetamine

Catha edulis Forsk

Neurobehavioral effects

\begin{abstract}
A B S T R A C T
Although there is a rich body of research available regarding the effect of acute and chronic khat dosing in animal models, research on the behavioral and cognitive effects of khat in human subjects is not extensive and several of the available studies have been done only in the context of observational and single-case studies. In light of the absence of a substantial literature on the neurobehavioral deficits associated with khat use and to provide a context that could be used to identify themes for future research we review previous research that has focused on other stimulant drugs. This review highlights multiple areas of neurocognitive deficit that have been identified in previous studies of individuals who have been chronic users of stimulants, such as amphetamines and methamphetamines. The review highlights a substantial body of evidence demonstrating a wide range of learning and memory impairments including deficits that persist during abstinence from active drug use. This review does not imply a similar khat effect, but due to some similarities pharmacologically between the active components of khat (cathinone and cathine) and amphetamines, future studies examining these same domains of cognitive functioning in chronic khat users and abstinent khat users appears to be warranted, if possible using some of the same or similar laboratory measures.
\end{abstract}

(C) 2010 Elsevier Ireland Ltd. All rights reserved.

\section{Introduction}

The stimulant leaf khat (Catha edulis Forsk) comes from a tree which grows in countries bordering the Red Sea, along the east coast of Africa and in west Asia (Cox and Rampes, 2003; Balint et al., 2009). Catha edulis is popularly known as "khat" but is also known as "kat", "qat", "qad”, "qaad". "jaad", and "miraa”. This alkaloidcontaining psychostimulant plant is commonly used in East Africa and the Arabian Peninsula (Balint et al., 1991; Banjaw and Schmidt, 2006), as well as by immigrants from these regions who reside in Western countries, primarily Great Britain and the United States (Bhui et al., 2003; Warfa et al., 2007). Khat is chewed habitually by users for its euphoric effects and as a recreational drug, and chewing khat has an important role as well in both traditional and religious ceremonies (Banjaw and Schmidt, 2005, 2006).

Chewing is the most common mode of administration (Cox and Rampes, 2003), although a small number of users use dried leaves to make drinks and an equally small number smoke it (Pantelis et al., 1989). The traditional way to consume khat is to pick a few leaves of a young shoot and chew them slowly. Once the leaves are pulped, they are kept in the side of the cheek and the mouth is filled with fresh leaves. The user then chews slowly and intermittently to release the active components of khat that are then swallowed

\footnotetext{
* Corresponding author. Tel.: +1 218726 8874; fax: +1 2187267559

E-mail address: rhoffman@d.umn.edu (R. Hoffman).
}

with saliva (Cox and Rampes, 2003), periodically ingesting fresh leaves (Banjaw and Schmidt, 2005).

The psychostimulant component of khat is cathinone, which is released within 15-45 min during chewing (Graziani et al., 2008). A khat chewing session, however, may last 3-7 h (Banjaw and Schmidt, 2005). Khat chewing has a social and cultural tradition, and it may occur while in the company of others or alone (Balint et al., 2009). It is highly prevalent in many countries in Africa and Asia, with $75 \%$ of men using khat in some countries (Alem et al., 1999). About 20 years ago, it was estimated that around 10 million people commonly used khat in East Africa and Arabian Peninsula countries (Balint et al., 1991), but there is some evidence to suggest that use may be increasing. In 1996, it was estimated that worldwide approximately 6 million individual portions of khat were consumed daily (Kalix, 1996). Recent reports indicate that $80-90 \%$ of East African males use khat on a daily basis and $10-60 \%$ of East African females use khat on a daily basis (Numan, 2004; Odenwald et al., 2005; Warfa et al., 2007). In Ethiopia, recent estimates of prevalence (Alem et al., 1999) approach $50 \%$, with $17 \%$ self-described as daily users, predominantly men (a reported 5:1 male to female ratio).

While early reports indicated greater prevalence in men than in women, recent reports - including those by members of our group - have shown sharp increases in khat use by women in some countries, including Yemen (Griffiths, 1998; Khalil, 1998). The prevalence of khat use has also been climbing in several communities in Europe and North America (Griffiths, 1998). Interestingly there is evidence to suggest that the gender differences in khat 
use disappear in Western countries. A recent survey conducted in London, UK, showed that $78 \%$ of men and $76 \%$ of women of Somali background had used khat, with $76 \%$ of participants reporting using more khat in London than they had in Somalia (Griffiths, 1998). Historically, khat is used near where it is grown, but advanced land and air transportation and recent immigrations have allowed a much wider distribution around the world, including distribution in Europe and North America.

Users of khat report feeling as if they are able to think more clearly and more quickly while chewing khat, and also report increased energy, increased confidence, a general sense of wellbeing, decreased hunger and fatigue, and the increased ability to easily converse with others. Other self-reported acute effects of khat include increased levels of alertness, enhanced ability to concentrate, friendliness, contentment and flow of ideas (Cox and Rampes, 2003; Balint et al., 2009). This is usually followed by excessive tension, anxiety, emotional instability, irritability, and restlessness within $2 \mathrm{~h}$, followed by feelings of low mood, numbness, lack of concentration, sluggishness, and insomnia.

\section{Pharmacology of khat}

Research initiatives sponsored by the World Health Organization have fostered scientific studies designed to understand the pharmacology of khat. This research has demonstrated that khat leaves contain cathinone, a psychostimulant that is similar in structure and pharmacological activity to amphetamine (Kalix, 1992, 1994). Due to these similarities, cathinone has been called a 'natural amphetamine' (Kalix, 1996). Cathinone or more properly S-(-) cathinone has been characterized as an amphetamine-like sympathomimetic amine (Kalix, 1996) with a half-life of approximately $3 \mathrm{~h}$ in humans (Widler et al., 1994; Toennes et al., 2003). Cathinone reaches a maximum plasma level $1-2 \mathrm{~h}$ after oral administration; the effect of cathinone on the user occurs more rapidly than the effect of amphetamine, roughly $15 \mathrm{~min}$ as compared to $30 \mathrm{~min}$ (Cho and Kumagai, 1994). In addition to cathinone, cathine or D-norpseudoephedrine has been identified as an additional psychoactive ingredient in khat (Graziani et al., 2008), and cathine has also been noted to have psychostimulant properties. Although cathinone appears to be only half as potent as amphetamine and cathine is roughly 7-10 times less potent than amphetamine, the well-developed scientific literature examining the acute and chronic neurobehavioral effects of amphetamine and methamphetamine may provide a model to guide future research related to the acute and chronic effects of khat use.

Similar to psychostimulants, khat ingestion produces several central nervous system effects, including increased motor stimulation, euphoria, and a sense of excitement and energy (Widler et al., 1994; Kalix, 1996; Nencini et al., 1998). It also results in decreased appetite and increased blood pressure and heart rate. These effects indicate that khat acts through similar central mechanisms as other stimulants. For example, both cathinone and amphetamine increase the activity of the dopaminergic and noradrenergic transmission (Pehek and Schechter, 1990; Pehek et al., 1990; Patel, 2000). While the nature of khat dependence remains under active debate, there is accumulating evidence indicating the existence of a withdrawal syndrome and a low level of tolerance. Withdrawal symptoms usually include inertia, nightmares, trembling, depression, sedation and hypotension (Cox and Rampes, 2003).

\section{Khat use, health and neurological functioning}

Over the years epidemiological and case control studies have indicated a clear association between long-term khat use and cardiovascular, respiratory, gastrointestinal, obstetric, metabolic, endocrine, and nervous system dysfunction (Nasher et al., 1995; elShoura et al., 1995; Dalu, 2000; Hassan et al., 2000; Al Habori and Al Mamary, 2004; Al Habori, 2005; Hassan et al., 2005). Reviews of research on the relationship between khat use and cardiovascular functions have indicated increased sympathetic activity (Widler et al., 1994; Hassan et al., 2000), increased pulse rate, increased arterial pressure, and increased risk for acute myocardial infarction (Al-Motarreb et al., 2002). It has been reported that khat users in Yemen have a higher incidence of esophageal cancer (Balint et al., 2009). Evidence of obstetric problems of khat users indicates that khat use during pregnancy is associated with low birth weight and impaired lactation (Mwenda et al., 2003). Although chronic use of khat associated with brain problems have not been carefully studied, evidence from the study of other similar drugs of abuse suggests that individuals who have been chronically exposed to drugs of abuse show both structural and functional brain changes (Yucel and Lubman, 2007; Yucel et al., 2007). Neurobiological changes due to chronic drug use vary as a function of many factors, however, including the class of drugs and the pattern of use, as well as the complex interplay with preexisting neurodevelopmental factors. For example, there is some evidence to suggest that primates that have pre-existing lowered D2 receptor densities are at increased risk to use cocaine and become addicted (Nader et al., 2006) and similar results have been reported in the rodent model (Dalley et al., 2007). In similar fashion, humans that are chronic users of cocaine may be more likely to have pre-existing problems in inhibitory control (Bechara, 2005) and impulsivity (Verdejo-Garcia et al., 2008). A similar relationship may well exist between pre-existing conditions and behavior patterns of khat users, which must be considered in future studies.

One primary structure that has been implicated in drug-related deficits across multiple studies is the prefrontal cortex, accounting for various cognitive, behavioral, and emotion regulation deficits. Impairments in these domains may particularly be evidenced in individuals who use multiple drugs, or who are exposed to other high risk environmental conditions.

\section{Cognitive and behavioral deficits associated with khat use}

Research on behavioral and cognitive problems following khat use in humans is not extensive and several of the available studies have been done only in the context of observational and single-case studies. Khat users report that they use this substance to improve their performance, stay alert, and to increase their energy (Cox and Rampes, 2003). Preliminary observations suggest that chronic use of khat is associated with various cognitive and mental health impairments, however (Odenwald, 2007; Odenwald et al., 2007; Balint et al., 2009; Odenwald et al., 2009). Central nervous system deficits associated with khat use include impaired concentration, insomnia, headaches, migraine, midriasis, conjunctival congestion, impaired motor coordination, fine tremor, stereotypical behavior (Al-Motarreb et al., 2002).

Other indirect observations also indicate long-term effects that range from insomnia, anxiety, irritability, agitation and aggression to major problems such as schizophreniform psychotic disorder, paranoid delusions, mania, and depression, as well as an apparent increase in suicidal depression and an increased relative risk of hallucinations (Yousef et al., 1995; Alem and Shibre, 1997; Odenwald et al., 2005; Odenwald, 2007; Balint et al., 2009). These effects are similar to those observed in amphetamine users. Recent evidence suggests a possible synergistic relationship between khat use and post-traumatic stress disorder as a risk factor for paranoia (Odenwald et al., 2007, 2009). 
While there is no specific neuropsychological data on the acute or chronic effects of khat, research with other stimulants may provide a perspective. Acute $\mathrm{D}$-amphetamine administration improves certain tasks, such as vigilance tasks (Koelega, 1993; Comer et al., 1996) and attention (Cami et al., 2000; de Wit et al., 2002), but impairs performance on visual scanning tasks (Silber et al., 2006). Research has also shown amphetamine to have negative effects on sensorimotor gating (Hutchison and Swift, 1999), reflecting deficits in the ability to filter out irrelevant or intrusive stimuli, which subsequently causes an overload of information (Swerdlow and Geyer, 1998). It is possible that khat produces similar effects on cognitive performance, although perhaps to a lesser extant.

One of the significant implications of these possible khatrelated effects is that related to erratic and unstable driving, possibly leading to increased traffic accidents and related fatalities. It is worth noting that Yemen, where khat is widely used by drivers, is ranked among the highest in both the number of vehicular accidents and the number of deaths from these accidents worldwide, despite frequent campaigns for traffic safety sponsored by local and international organizations (Ameen and Naji, 2001). Although khat has a stimulating effect that reportedly enhances attention and performance during the first few hours of use, it may still be a culprit in increasing the risk for road accident fatalities due to increased anxiety and tension that usually appears after several hours of use and due to users engaging in distracting behaviors such as drinking water, smoking, or preparing and cleaning the khat leaves while driving (Ameen and Naji, 2001).

Toennes and Kauert (2004) analyzed the results of 19 forensic vehicular cases in which the use of khat was detected, observing that impaired driving was suggested in 10 of the 19 cases, with observed symptoms by on scene police personnel that were in agreement with effects of indirect sympathomimetic agents including khat-alkaloids (impaired coordination, impaired balance, slow pupil reaction to light, impairment of divided attention, and tremor and balance problems in some cases). They concluded that chronic khat use may lead to a marked deterioration of psychophysical functions, including those relevant to driving vehicles in a safe manner. Presumably, impairments such as this would hamper the operation of heavy machinery, assembly and factory tasks, affect some military operations, and affect many tasks that require vigilance, divided attention, visual scanning, and motor coordination. There is a clear need to further investigate what appears to be a serious potential public safety issue in carefully controlled laboratory experiments.

\section{Effects of long-term khat use}

Some limited studies and single case reports suggest longterm effects of khat on behavioral and cognitive functions. These effects range from minor to major psychiatric problems. Minor effects include insomnia, anxiety, irritability, agitation and aggression. Other documented psychiatric effects include a shortlived schizophreniform psychotic illness and mania (Yousef et al., 1995; Odenwald, 2007). Use of excessive amount of khat has also been was found to significantly increase the risk for psychosis or psychotic-like episodes (Alem and Shibre, 1997; Odenwald et al., 2005; Warfa et al., 2007), including paranoid delusions and significant mania. These effects are similar to those observed in amphetamine users. Depression has also been frequently reported to be related to long-term use of khat and seems to be particularly evident during cessation (Odenwald, 2007).

\section{Concurrent use of khat and other drugs of dependence}

\subsection{Concurrent use of khat and tobacco}

During khat chewing sessions, users consume large quantities of tobacco. We have observed that approximately $55 \%$ of khat users are also regular smokers, and this is supported by a study with medical students at Aden University showing $42 \%$ of khat chewers were heavy smokers, and $9.3 \%$ of the participants reported smoking only when they chewed khat (Bawazeer et al., 1999). Griffiths (1998) has shown that $60 \%$ of khat chewers also smoked cigarettes. The extent to which concurrent use of khat and tobacco interacts in influencing cognitive or stress-related biobehavioral functions is not known. Studies examining effects of tobacco have shown that long-term smoking contributes to dysregulation of the neurobiological response, and that acutely nicotine affects stress response hormonal and physiological measures. Acutely, nicotine enhances psychomotor performance, such finger tapping (Perkins et al., 1990) and sustained attention (Mumenthaler et al., 1998; Harakas and Foulds, 2002). On the other hand, cognitive deficits have been observed during abstinence from cigarette smoking (al'Absi et al., 2002).

There may be a complex interaction between the presumed amphetamine-like effects of khat use and tobacco use. Although both amphetamine and nicotine are dopamine agonists, there are observed differences in their effects on behavioral measures. Amphetamine has been observed to improve performance on cognitive processes such as attention and psychomotor functioning, but appears to impair performance in other areas of cognitive functioning, such as those requiring visual scanning or the ability to filter out irrelevant information (Silber et al., 2006). It is possible that the use of both khat and tobacco presents greater risk than use of khat alone on emotion regulation and cognitive functions. Further investigation in this area is relevant to research focusing on concurrent addictive behaviors in other countries related to the comorbidity of tobacco and alcohol dependence (John et al., 2003; Hurt and Patten, 2003) and the comorbidity of tobacco and marijuana use (Lai et al., 2000; Burns et al., 2000; Humfleet and Haas, 2004).

\subsection{Concurrent use of khat and alcohol}

Due to the acute stimulating effects of khat and its effects on mood and sleep, khat users may also use alcohol as a method to calm down. One early study that investigated alcohol and khat use in Kenya found that more than two thirds of khat users use alcohol and $41 \%$ of khat users drank alcohol heavily (Dhadphale and Omolo, 1988). More recently, Kebede et al. (2005) reported that a significant number of their sample of Ethiopian youth between the ages of 15 and 24 used both khat and alcohol. Gelaw and HaileAmlak (2004) reported that 59\% of their sample of adult University workers in Ethiopia used alcohol after chewing khat, primarily to avoid insomnia and to decrease unpleasant feelings and depression. Selassie and Gebre (1996) and Nabuzoka and Badhadhe (2000) have also reported polydrug use in some khat users, primarily the use of alcohol and benzodiazapines.

\section{Effects of stimulants on human performance}

In light of the absence of a substantial literature on the neurobehavioral effects of khat on human performance and to provide a context that could be used to identify themes for future research, we next briefly review the available scientific literature regarding the effects of amphetamine on human neurobehavioral functions. This review does not imply a similar khat effect. Rather, in light 
of some common psychostimulant properties between these substances, previously observed effects of other stimulants should be considered when developing future hypotheses for studies of the neurobehavioral effects of khat.

\section{Neurocognitive deficits associated with acute amphetamine use}

Acute use of amphetamines and methamphetamines results in a number of effects on the sympathetic branch of the autonomic nervous system including hypertension, tachycardia, hyperthermia, increased breathing rate, and constriction of blood vessels. The acute cognitive and emotional effects of amphetamine use are similar to those reported by khat users including feelings of euphoria, enhanced energy and alertness, feelings of increased physical and mental capacity, and the belief by the user that they are experiencing a surge in productivity (Hart et al., 2001; Cretzmeyer et al., 2003). A sense of elevated self-esteem and increase in libido are also fairly common with acute amphetamine use. These effects may last from 8 to $13 \mathrm{~h}$, roughly equivalent to the half-life of methamphetamine (Busto et al., 1989). Repeated use or binge use of methamphetamines is quite common in chronic users, however, and in these instances methamphetamines may be repeatedly taken over the course of hours or even days. During binge use, users may exhibit an increase in sexual behaviors and repetitive, focused activities such as mechanical work or intense periods of cleaning, very commonly accompanied by sleeplessness (Semple et al., 2003). The progressively higher doses of methamphetamine needed to maintain a drug "high" with binge use can result in heightened anxiety, paranoia, hallucinations, and possibly frank delirium (Harris and Batki, 2000).

As a binge progresses, the positive effects of amphetamines generally become less pleasurable, while toxic effects become more prominent, and individuals eventually experience a phase characterized by increased anxiety, irritability, insomnia, and confusion. A withdrawal syndrome can occur at the termination of binge use and can include dysphoria, depression, irritability, anxiety, poor concentration, hypersomnia, fatigue, paranoia, akathisia, and drug craving (Barr et al., 2002; Zweben et al., 2004). Although a causal relationship has not been adequately demonstrated, methamphetamine use is frequently associated with increased impulsive, violent, and even homicidal behavior, as well as unsafe automobile driving. Clinical studies present a complex picture regarding the acute effects of methamphetamine on cognition. A number of studies have reported an enhancement of cognitive performance with acute administration of therapeutic doses, especially increases in information processing speed, psychomotor functioning, and attention, in both non-drug using volunteers (Johnson et al., 2000; Silber et al., 2006) and stimulant-dependent individuals (Johnson et al., 2005). However, other studies have shown equivocal effects and there is also evidence to suggest that acute doses of methamphetamines lead to deficits in inhibition and the ability to filter out irrelevant information (Comer et al., 2001).

In summary, the existing literature on acute cognitive effects of methamphetamine and amphetamine, combined with qualitative reports regarding use (Soetens et al., 1995), points to some potential increase in attentiveness and speed of processing possibly accompanied by disinhibition and a decrease in the ability to filter information at therapeutic doses.

\section{Neurocognitive deficits associated with chronic amphetamine use}

\subsection{Psychiatric symptoms}

Chronic methamphetamine abusers have high rates of affective distress and psychiatric disorders, which can be especially severe during withdrawal (Newton et al., 2004). Psychosis, including both negative and positive symptoms, is more likely to occur in methamphetamine abusing individuals compared to non-abusing populations, even after adjusting for history of psychotic disorders (Iwanami et al., 1994; Harris and Batki, 2000; Srisurapanont et al., 2003; McKetin et al., 2006). Individuals with a predisposition to psychotic symptoms, including schizotypal or schizoid traits and family histories of psychotic disorders, also have an increased risk of methamphetamine-associated psychosis (Chen et al., 2003, 2005). The presence of psychosis is usually transient, occurring during use or withdrawal and normally abating in a period of days. However, susceptibility to psychotic episodes may persist for years after cessation of methamphetamine use (Ujike and Sato, 2004). Methamphetamine users are also at increased risk of depression and suicidal ideation during active use, withdrawal, and abstinence, and this risk is amplified in women (Kalechstein et al., 2000; Zweben et al., 2004). Methamphetamine users may also have increased rates of antisocial personality disorder (Chen et al., 2003), as well as mania and bipolar disorder (Shoptaw et al., 2003).

\subsection{Neurocognitive deficits}

A number of studies have suggested that chronic methamphetamine use is associated with mild to moderate neuropsychological impairment, with one current estimate suggesting that approximately $40 \%$ of persons with methamphetamine dependence demonstrate some level of global neuropsychological impairment (Rippeth et al., 2004). Significant deficits in several different cognitive processes dependent upon brain frontostriatal and limbic circuits have been observed in studies of chronic methamphetamine users, including deficits in psychomotor functions, complex information processing speed, attention and working memory, episodic memory, and executive functions, including response inhibition and novel problem-solving (Rogers et al., 1999a,b; Ornstein et al., 2000; Salo et al., 2001; Volkow et al., 2001a; Simon et al., 2000, 2002, 2004; Salo et al., 2002; Sim et al., 2002; Paulus et al., 2002; Gonzalez et al., 2004; Woods et al., 2005).

\subsection{Complex information processing speed}

Some chronic methamphetamine users evidence modest visuoconstruction deficits on such tasks as the Rey Complex Figure copy task (Kalechstein et al., 2003). Some methamphetamine abusers also demonstrate impaired performance on tasks of perceptual speed and information manipulation, and also do very poorly on tasks that combine these skills with visuomotor scanning (Simon et al., 2002). It is unclear whether these seeming deficits are related to perceptual organizational impairment, executive dysfunction, constructional dyspraxia, or some combination of these (Scott et al., 2007). This area of cognitive functioning has not been examined in the khat user population.

\subsection{Attention and working memory}

Clinically, methamphetamine-dependent subjects appear distractible and exhibit difficulties in sustaining attention. This has been reported anecdotally in khat users as well, although this area of cognitive functioning has not been carefully examined in the laboratory setting. Chronic amphetamine users demonstrate impairments on some laboratory tasks involving attention and/or sustained attention. Attentional deficits have been noted in the Stroop Color Word and Trailmaking Tests (Simon et al., 2000; Kalechstein et al., 2003). Chronic methamphetamine users also exhibit deficits on measures of sustained attention and vigilance such as the CPT or Continuous Performance Test (Borgaro et al., 2003). A recent study completed by London et al. (2005) 
demonstrated that methamphetamine users made significantly more errors on an auditory version of the CPT than drug-free controls. These investigators noted that the signal detection index was significantly smaller in methamphetamine users than in controls, suggesting impairment in the ability to discriminate targets from non-targets. This suggests that the primary explicit attentional deficits in methamphetamine users may be related to reduced cognitive inhibition (Salo et al., 2002) and an inability to suppress irrelevant task information (Nordahl et al., 2003).

Deficits may also emerge on tasks with more complex processing demands that also involve working memory and decision-making, such as an N-back task (London et al., 2005). Individuals with a history of methamphetamine use display working memory deficits in such tasks as the immediate recall component of the auditory verbal learning test (Volkow et al., 2001a) and take 18-30\% longer to complete the working memory components of the California computerized assessment package (Chang et al., 2002). Chang et al. (2002) has suggested that this impairment may be directly related to task complexity.

Nordahl et al. (2003) examined the attentional performance of a group of methamphetamine-dependent subjects using a sensitive, computerized battery of selective attention tasks to better understand the nature and specific properties of this cognitive dysfunction (Salo et al., 2001). A single-trial Stroop priming task; a task switching experiment with response conflict trials; a spatial priming task; and a go-no-go task were all used in this assessment. When compared to controls, methamphetamine-dependent subjects displayed more consistent patterns of difficulties in suppressing irrelevant task information. These deficits were reflected in both reaction time measures and accuracy rates. Although the methamphetamine-dependent subjects in this experiment exhibited deficits in the explicit components of these tasks, they had preserved attentional priming.

\subsection{Episodic memory}

Extensive use of methamphetamines has also been repeatedly associated with deficits in episodic memory. This area of cognitive functioning has not been examined in the khat user population. The deficits seen in chronic methamphetamine users are most evident as impairment in word recall tasks, which measure recall at specific times after stimulus presentation (Simon et al., 2000; Volkow et al., 2001a; Thompson et al., 2004). Memory impairment in chronic amphetamine users appears to be related to self-reported severity of drug use (McKetin and Mattick, 1998). The marked deficits in episodic memory seen with chronic methamphetamine use are also among the most susceptible cognitive functions to methamphetamine relapse (Simon et al., 2004). Chronic use of amphetamines appears to have a larger negative effect on learning as compared with delayed recall, suggesting that impairment in learning (and perhaps retrieval) rather than consolidation or retention difficulties underlies the overall episodic memory deficit.

Woods et al. (2005) recently demonstrated impairment in overall learning, free recall, utilization of semantic clustering strategies, repetitions, and non-semantically related intrusion errors in 87 persons with methamphetamine dependence, who were nonetheless normal in retention and recognition discrimination. Woods and colleagues have demonstrated that, although there is an episodic memory deficit seen in methamphetamine users on the Hopkins Verbal Learning Test, it is of a strategic nature (executive, planning and organizational) and is not purely mnemonic (Woods et al., 2005). Moreover, Volkow et al. (2001b,c) showed associations between reduced striatal dopamine terminal function and deficits in list learning and recall in a sample of methamphetamine users. Taken together, these data support the notion that methamphetamine use may disrupt the organizational and technical components of memory encoding and retrieval that are dependent upon brain fronto-striatal pathways. It is not clear whether other aspects of learning and memory that depend upon these same pathways are similarly affected, such as the prospective memory component of episodic memory or non-declarative (procedural) memory (Scott et al., 2007).

\subsection{Executive functions}

A recent meta-analysis (Scott et al., 2007) noted the presence of significant executive dysfunction in chronic methamphetamine users across several studies, with observed Wisconsin Card Sorting Test perseverations, Stroop Color-Word interference, and reduced performance on Part B of the Trailmaking Test. This area of cognitive functioning has not been examined in the khat user population.

Impairments in executive function, which include the cognitive domains of abstract reasoning, planning, and behavioral flexibility, are evident in methamphetamine users on the Stroop Interference Task (Kalechstein et al., 2003) as well as the Behavioural Assessment of the Dysexecutive Syndrome - BADS test (Verdejo-Garcia and Perez-Garcia, 2007a). These deficits may reflect underlying episodic memory deficits or might indicate problems with response inhibition and/or cognitive set shifting. Moderate language impairment has been demonstrated in chronic methamphetamine users, which may be partially explained by information processing speed deficits and executive function impairments. This language impairment is apparent on measures of verbal fluency which require rule-guided generation of words under time constraints, such as the Controlled Oral Word Association Test (COWAT). This verbal fluency deficit may reflect executive dyscontrol of search and retrieval strategies or generally slowed information processing speed (Scott et al., 2007).

There is a growing body of evidence to also suggest that chronic methamphetamine users evidence significant problems with impulsivity and impaired decision-making capabilities. Methamphetamine-dependent individuals exhibit risky decisionmaking and impulse control problems as demonstrated by their sensitivity to immediate versus delayed rewards (Hoffman et al., 2006; Monterosso et al., 2006), selection of impulsive choices when compared to normal controls (Gonzalez et al., 2007), and self-report of impulsive behavior patterns (Semple et al., 2004, 2005). Several investigators (Grant et al., 2000; Bechara et al., 2001; Pirastu et al., 2006; Verdejo-Garcia and Perez-Garcia, 2007b) have noted that chronic amphetamine users have an increase in the use of disadvantageous decision-making strategies on the Iowa Gambling Task (Bechara et al., 1997). Similar results have been found with performance on the Cambridge Gamble Task (Rogers et al., 1999a,b), in that chronic amphetamine users showed disadvantageous decision-making and selected a likely small reward option less frequently than controls (85\% of trials versus 95\%), which may reflect an impairment in correctly estimating outcome probabilities (Ersche and Sahakian, 2007). Comparable results have been reported by Ersche et al. (2005) regarding the performance of chronic amphetamine abusers on the Risk Task (Rogers et al., 1999a). These seeming decision-making deficits may be related to the executive functioning aspects of working memory deficits (Bechara and Martin, 2004).

Studies with current amphetamine/methamphetamine users have shown marginal to severe impairment on tests of cognitive flexibility, such as the Wisconsin Card Sorting Test (Ornstein et al., 2000; Simon et al., 2002) and the intra-dimensional/extradimensional (IDED) set-shifting task of the CANTAB test battery (Downes et al., 1989; Rogers et al., 2000). There is recent evidence which suggests that the impaired cognitive flexibility in methamphetamine users, however, may be associated with male, but not female, gender (Kim et al., 2005). Although these deficits were 
seen in active, chronic amphetamine/methamphetamine users (Ornstein et al., 2000; Simon et al., 2000; Ersche et al., 2006), there is some evidence to suggest that these deficits may not be present in abstinent amphetamine/methamphetamine users (Hoffman et al., 2006). Growing evidence indicates that inhibitory cognitive control on such tasks as the Stroop test (Stroop, 1992) is compromised in amphetamine users (Salo et al., 2002, 2007; Simon et al., 2002). Some studies, however, have not found impaired interference control in recently abstinent methamphetamine users (Chang et al., 2002; Kalechstein et al., 2003; Hoffman et al., 2006), which may represent partial recovery of brain function following abstinence from methamphetamine (Ersche and Sahakian, 2007).

Monterosso et al. (2005) have reported that chronic methamphetamine users demonstrate deficits in behavioral inhibition on the Stop-Signal Reaction Time task (Logan, 1994; Evenden, 1999; Dougherty et al., 2003; Hom et al., 2003). Methamphetamine users have a significantly longer stopping process than controls and a significantly longer stop-signal reaction time, suggesting that response inhibition is compromised in these psychostimulant users independent from attentional processing. Inhibition failure on the Stop-Signal task appears to be associated with the previous amount of methamphetamine consumed (Monterosso et al., 2005), and may reflect dose-dependent neuroadaptive changes underlying poor behavioral inhibition in chronic users of methamphetamine.

Strategic planning and the ability to think ahead and actively search for an appropriate solution to a given problem or to mentally organize behavior to achieve a goal through a series of intermediate steps appears to be impaired in chronic amphetamine users. Amphetamine users, regardless of current drug status, solved significantly fewer problems correctly on the one-touch Tower of London Test (Owen et al., 1995), and therefore needed more attempts in order to generate correct answers compared to controls (Ornstein et al., 2000; Ersche et al., 2006). Amphetamine users also struggled to generate solutions for the relatively easy three-move Tower of London Test (Ersche et al., 2006). The first 1-3 stages of the Tower of London require little true planning ability, since they can be easily solved by a visual matching-to-sample strategy (Owen, 1997), so it is conceivable that the poor performance of amphetamine users at this low level of difficulty may represent either an over-confident approach to the solution of the problem or an inefficiency in concentrating on the task demands (Ersche and Sahakian, 2007). Amphetamine users have also shown marked impairment on similar but more complicated tasks requiring complex spatial working memory function and visuo-spatial strategy generation (Ornstein et al., 2000).

\section{Persistent cognitive deficits in abstinent amphetamine-dependent subjects}

Marked impairment in some areas of neurocognitive functioning of methamphetamine-dependent patients may persist into abstinence, be slow to normalize, and may actually worsen initially (Meredith et al., 2005). Methamphetamine-dependent individuals in early abstinence (5-14 days) perform markedly worse than controls on measures of attention and psychomotor speed (Trailmaking Test Part A, Symbol Digit Modalities Test, Stroop Color), and measures of verbal learning and memory (Rey Auditory Learning Test, WMS III Logical Memory) and figural memory (Rey Complex Figure 30 min delay), as well as on fluency-based measures of executive function that included set shifting and inhibition (Kalechstein et al., 2003). There is evidence that verbal memory performance improves following protracted drug abstinence, however (Wang et al., 2004). Decrements in performance on psychomotor and verbal memory tasks lessen in methamphetamine-dependent subjects after 3-14 months of abstinence (Volkow et al., 2001b), but these individuals continue to perform significantly worse on working memory tasks after 6-10 months of abstinence compared to controls (Chang et al., 2002).

Also, despite 2 months of abstinence, methamphetamine abusers consistently demonstrate errors in selective attention and priming (Salo et al., 2002). After 3 months of abstinence, recovering methamphetamine abusers score worse on word recognition tests and tests of episodic memory than do individuals who continue to use methamphetamines, who themselves do worse than methamphetamine-naïve controls (Simon et al., 2004).

\section{Suggested future neurocognitive research with chronic khat users}

Multiple areas of neurocognitive deficit have been identified in previous studies of individuals who have been chronic users of stimulants, such as amphetamines and methamphetamines, including deficits that persist during abstinence from active drug use. A substantial body of evidence has demonstrated a wide range of learning and memory impairments in chronic amphetamine and methamphetamine users (Ornstein et al., 2000; Simon et al., 2002; Kalechstein et al., 2003; Gonzalez et al., 2004; Rippeth et al., 2004; Woods et al., 2005; Ersche et al., 2006; Hoffman et al., 2006; Moon et al., 2007). Recent evidence from rodent research implicates a similar association between daily khat use and spatial learning and memory (Kimani and Nyongesa, 2008) as well as behavioral sensitization with repeated dosing (Kimani et al., 2008). Due to some similarities pharmacologically between the active components of khat (cathinone and cathine) and amphetamines, future studies examining these same domains of cognitive functioning in chronic khat users and abstinent khat users appears to be warranted, if possible using some of the same or similar laboratory measures.

A recent meta-analysis of the neurocognitive deficits associated with users of methamphetamines (Scott et al., 2007) indicates that the largest (medium to large) effect sizes are seen in the domains of executive functions, learning, and memory. Medium effect sizes were seen in this same meta-analysis in the domains of motor skills and speed of information processing. This is consistent with other contemporary reviews of the neuropsychological effects of amphetamines and methamphetamines in humans (Nordahl et al., 2003; Ersche and Sahakian, 2007). Although numerous laboratory studies with animals have suggested that cathinone has a potential for abuse perhaps greater than amphetamine and causes persistent dependence with minimal withdrawal (Feyissa and Kelly, 2008), cathinone is nonetheless $50 \%$ less potent than amphetamine and this may also reduce the effect size seen in proposed future laboratory studies of human khat consumption. For this reason, it is recommended that initial human laboratory studies of the neurocognitive deficits associated with khat use focus on the domains of learning, memory, and executive functions.

It is therefore recommended that future studies consider specific examination of the neuropsychological domains of learning and episodic memory, working memory, set shifting/cognitive inhibition, cognitive flexibility, inhibitory control, strategic planning, and decision-making, with some potential for subsequent studies examining attention/psychomotor speed, sustained attention, visuoconstruction, verbal fluency, and nonverbal fluency (see Table 1). Suggestions for possible measures are listed in Table 1.

It should be noted, however, that many of these psychological and neuropsychological measures do not currently have adequate normative information for non-English speaking populations and there may be cultural barriers as well to their use.

Care should be taken in future khat research studies to account for the confounding factors of inadequate sample size and appropriate control for age, gender, education, measured intelligence, and 
Table 1

Potential areas of neurocognitive deficit in chronic khat users, based upon studies completed with chronic users of other stimulant drugs.

\begin{tabular}{|c|c|}
\hline $\begin{array}{l}\text { Domain of neuropsychological } \\
\text { functioning }\end{array}$ & Potential measures \\
\hline Learning and episodic memory & $\begin{array}{l}\text { RAVLT (Trials } 1-5 \text { ) } \\
\text { RAVLT Delayed Recall } \\
\text { WMS IV Logical Memory ( } 30 \text { min delay) } \\
\text { Rey Complex Figure Recall ( } 30 \text { min } \\
\text { delay) } \\
\text { Hopkins Verbal Learning Test }\end{array}$ \\
\hline Working memory & $\begin{array}{l}\text { Letter-Number Sequencing } \\
\text { Visual Memory Span - Backwards }\end{array}$ \\
\hline $\begin{array}{l}\text { Set shifting/cognitive } \\
\text { inhibition }\end{array}$ & $\begin{array}{l}\text { Trailmaking Test, Part B } \\
\text { Stroop Interference }\end{array}$ \\
\hline Cognitive flexibility & $\begin{array}{l}\text { Wisconsin Card Sorting Test } \\
\text { CANTAB set-shifting task (IDED) } \\
\text { Behavioural Assessment of the } \\
\text { Dysexecutive Syndrome - BADS test }\end{array}$ \\
\hline Inhibitory control & $\begin{array}{l}\text { Stop-Signal task } \\
\text { Go-Nogo Task }\end{array}$ \\
\hline Strategic planning & $\begin{array}{l}\text { Tower of London Test } \\
\text { One-Touch Tower of London Test }\end{array}$ \\
\hline Decision-making & $\begin{array}{l}\text { Iowa Gambling Task } \\
\text { Cambridge Gamble Task } \\
\text { Risk Task }\end{array}$ \\
\hline Attention/psychomotor speed & $\begin{array}{l}\text { Trailmaking Test Part A } \\
\text { Symbol Digit Modalities Test } \\
\text { Stroop - Color }\end{array}$ \\
\hline $\begin{array}{l}\text { Sustained attention } \\
\text { Visuoconstruction } \\
\text { Verbal fluency } \\
\text { Nonverbal fluency }\end{array}$ & $\begin{array}{l}\text { Continuous Performance Test (CPT) } \\
\text { Rey Complex Figure } \\
\text { Controlled Oral Word Association Test } \\
\text { Ruff Figural Fluency Test }\end{array}$ \\
\hline
\end{tabular}

polydrug use that have plagued previous studies on stimulant drug use in human subjects (Jovanovski et al., 2005). Careful screening of research subjects will be needed to identify those subjects in particular that concurrently use tobacco and/or alcohol, as well as drugs of abuse, especially benzodiazapines. It is recommended that studies of the relationship of neurocognitive functioning to khat use be carried out in a carefully controlled laboratory environment. There is a particular need for well designed human studies investigating the neurocognitive effects of acute khat dosing.

Several other areas of investigation should also be considered in the proposed future research agenda for human khat studies. Although the reported gender differences in khat use prevalence might be attributable to cultural roles or the availability of sufficient time to use khat, it would be worthwhile to investigate the potential role of hormones (particularly estrogen) as mediating factors. A number of recent studies in both humans (Munro et al., 2006) and non-human primates (Czoty et al., 2009) suggest that changes in DA receptor availability may be involved in the variation in symptoms of various neuropsychiatric disorders across the menstrual cycle, including differences in sensitivity to the abuse-related effects of stimulants.

Another emerging area of considerable interest in stimulant research and addiction is the role of pharmacogenetics related to drug response and human molecular genetics as an intervening variable in characterizing the response to addictive substances, including opiates, cocaine, and stimulants (Kendler et al., 2003; Kreek et al., 2005a,b). Particularly salient for khat researchers is the role that genetic influences may play in the neurocognitive domains of impulsivity, risk taking, and stress responsivity (Kreek et al., 2005a) which are central to the investigation of stimulant drugs such as khat.

\section{References}

al'Absi, M., Amunrud, T., Wittmers, L., 2002. Psychophysiological effects of abstinence and behavioral challenges in habitual smokers. Pharmacology Biochemistry and Behavior 72, 707-716.

Al Habori, M., Al Mamary, M., 2004. Long-term feeding effects of Catha edulis leaves on blood constituents in animals. Phytomedicine 11, 639-644.

Al Habori, M., 2005. The potential adverse effects of habitual use of Catha edulis (khat). Expert Opinion on Drug Safety 4, 1145-1154.

Alem, A., Shibre, T., 1997. Khat induced psychosis and its medico-legal implication: a case report. Ethiopian Medical Journal 35, 137-139.

Alem, A., Kebede, D., Kullgren, G., 1999. The prevalence and socio-demographic correlates of khat chewing in Butajira, Ethiopia. Acta Psychiatrica Scandinavica Supplement 397, 84-91.

Ameen, J., Naji, J., 2001. Causal models for road accident fatalities in Yemen. Accident Analysis and Prevention 33, 547-561.

Al-Motarreb, A., Baker, K., Broadley, K., 2002. Khat: pharmacological and medical aspects and its social use in Yemen. Phytotherapy Research 16, 403-413.

Balint, E., Falkay, G., Balint, G., 2009. Khat-a controversial plant. Wiener klinische Wochenschrift. The Middle European Journal of Medicine 121, 604-614.

Balint, G., Ghebrekidan, H., Balint, E., 1991. Catha edulis, an international sociomedical problem with considerable pharmacological implications. East African Medical Journal 68, 555-561.

Banjaw, M., Schmidt, W., 2005. Behavioural sensitisation following repeated intermittent oral administration of Catha edulis in rats. Behavioural Brain Research 156, 181-189.

Banjaw, M., Schmidt, W., 2006. Catha edulis extract and its active principle cathinone induce ipsilateral rotation in unilaterally lesioned rats. Behavioural Pharmacology $17,615-620$.

Barr, A., Markou, A., Phillips, A., 2002. A 'crash' course on psychostimulant withdrawal as a model of depression. Trends in Pharmacological Science 23, 475-482.

Bawazeer, A., Hattab, A., Morales, E., 1999. First cigarette smoking experience among secondary-school students in Aden, Republic of Yemen. East Mediterranean Health Journal 5, 440-449.

Bechara, A., 2005. Decision making, impulse control and loss of willpower to resist drugs: a neurocognitive perspective. Nature Neuroscience 8, 1458-1463.

Bechara, A., Damasio, H., Tranel, D., Damasio, A., 1997. Deciding advantageously before knowing the advantageous strategy. Science 275, 1293-1295.

Bechara, A., Dolan, S., Denburg, N., Hindes, A., Anderson, S., Nathan, P., 2001 Decision-making deficits, linked to a dysfunctional ventromedial prefrontal cortex, revealed in alcohol and stimulant abusers. Neuropsychologica 39, 376-389.

Bechara, A., Martin, E., 2004. Impaired decision making related to working memory deficits in individuals with substance additions. Neuropsychology 18,152 162.

Bhui, K., Mohamud, S., Warfa, N., Craig, T., Stansfeld, S., 2003. Cultural adaptation of mental health measures: improving the quality of clinical practice and research. British Journal of Psychiatry 183, 184-186.

Borgaro, S., Pogge, D., Deluca, V., Bilginer, L., Stokes, J., Harvey, P., 2003. Convergence of different versions of the continuous performance test: clinical and scientific implications. Journal of Clinical and Experimental Neuropsychology 25, 283-292.

Burns, C., Ives, R., Lindorff, K., Clough, A., 2000. Cannabis: a Trojan horse for nicotine? Australian and New Zealand Journal of Public Health 24, 637.

Busto, U., Bendayan, R., Sellers, E., 1989. Clinical pharmacokinetics of non-opiate abused drugs. Clinical Pharmacokinetics 16, 1-26.

Cami, J., Farre, M., Mas, M., Roset, P., Poudevida, S., Mas, A., San, L., de la Torre, R., 2000 Human pharmacology of 3,4-methylenedioxymethamphetamine ("ecstasy"): psychomotor performance and subjective effects. Journal of Clinical Psychopharmacology 20, 455-466.

Chang, L., Ernst, T., Speck, O., Patel, H., DeSilva, M., Leonido-Yee, M., 2002. Perfusion MRI and computerized cognitive test abnormalities in abstinent methamphetamine users. Psychiatry Research 114, 65-79.

Chen, C., Lin, S., Sham, P., Ball, D., el Loh, W., Murray, R., 2005. Morbid risk for psychiatric disorder among the relatives of methamphetamine users with and without psychosis. American Journal of Medical Genetics, Part B: Neuropsychiatric Genetics 136, 87-91.

Chen, C., Lin, S., Sham, P., Ball, D., Loh, E., Hsiao, C., 2003. Pre-morbid characteristics and co-morbidity of methamphetamine users with and without psychosis Psychological Medicine 33, 1407-1414.

Cho, A., Kumagai, Y., 1994. Metabolism of amphetamine and other arylisopropylamines. In: Cho, A.K., Segal, D.S. (Eds.), Amphetamine and Its Analogs: Psychopharmacology, Toxicology, and Abuse. Academic Press, San Diego, pp. 43-80.

Comer, S., Haney, M., Foltin, R., Fischman, M., 1996. Amphetamine selfadministration by humans: modulation by contingencies associated with task performance. Psychopharmacology (Berlin) 127, 39-46.

Comer, S., Hart, C., Ward, A., Haney, M., Foltin, R., Fischman, M., 2001. Effects of repeated oral methamphetamine administration in humans. Psychopharmacology $155,397-404$.

Cretzmeyer, M., Sarrazin, M., Huber, D., Block, R., Hall, J., 2003. Treatment of methamphetamine abuse: research findings and clinical directions. Journal of Substance Abuse Treatment 24, 267-277.

Cox, G., Rampes, H., 2003. Adverse effects of khat: a review. Advances in Psychiatric Treatment 9, 456-463.

Czoty, P., Riddick, N., Gage, H., Sandridge, M., Nader, S., Garg, S., Bounds, M., Garg, P., Nader, M., 2009. Effect of menstrual cycle phase on dopamine D2 recep- 
tor availability in female cynomolgus monkeys. Neuropsychopharmacology 34, 548-554.

Dalley, J., Fryer, T., Brichard, L., Robinson, E., Theobald, D., Laane, K., Pena, Y., Murphy, E., Shah, Y., Probst, K., Abakumova, I., Aigbirhio, F., Richards, H., Hong, Y., Baron, J., Everitt, B., Robbins, T., 2007. Nucleus accumbens D2/3 receptors predict trait impulsivity and cocaine reinforcement. Science 315, 1267-1270.

Dalu, A., 2000. The impact of long term consumption of khat on public health. The Sidama Concern 5, 15-16 (on-line).

de Wit, H., Enggasser, J., Richards, J., 2002. Acute administration of D-amphetamine decreases impulsivity in healthy volunteers. Neuropsychopharmacology 27, 813-825.

Dhadphale, M., Omolo, O., 1988. Psychiatric morbidity among khat chewers. East African Medical Journal 65, 355-359.

Dougherty, D., Bjork, J., Harper, R., Marsh, D., Moeller, F., Mathias, C., Swann, A., 2003. Behavioral impulsivity paradigms: a comparison in hospitalized adolescents with disruptive behavior disorders. Journal of Child Psychology and Psychiatry 44, 1145-1157.

Downes, J., Roberts, A., Sahakian, B., Evenden, J., Morris, R., Robbins, T., 1989 Impaired extra-dimensional shift performance in medicated and unmedicated Parkinson's disease: evidence for a specific attentional dysfunction. Neuropsychologica 27, 1329-1343.

el-Shoura, S., Abdel Aziz, M., Ali, M., el-Said, M., Ali, K., Kemeir, M., Raoof, A., Allam, M., Elmalik, E., 1995. Deleterious effects of khat addiction on semen parameters and sperm ultrastructure. Human Reproduction 10, 2295-2300.

Ersche, K., Sahakian, B., 2007. The neuropsychology of amphetamine and opiate dependence: implications for treatment. Neuropsychology Review 17, 317-336.

Ersche, K., Clark, L., London, M., Robbins, T., Sahakian, B., 2006. Profile of executive and memory function associated with amphetamine and opiate dependence. Neuropsychopharmacology 31, 1036-1047.

Ersche, K., Fletcher, P., Lewis, S., Clark, L., Stocks-Gee, G., London, M., Deakin, J., Robbins, T., Sahakian, B., 2005. Abnormal frontal activations related to decisionmaking in current and former amphetamine and opiate dependent individuals. Psychopharmacology 180, 612-623.

Evenden, J., 1999. Varieties of impulsivity. Psychopharmacology 146, 348-361.

Feyissa, A., Kelly, J., 2008. A review of the neuropharmacological properties of khat. Progress in Neuro-Psychopharmacology and Biological Psychiatry 32 1147-1166.

Gelaw, Y., Haile-Amlak, A., 2004. Khat chewing and its socio-demographic correlates among the staff of Jimma University. Ethiopian Journal of health Development $18,179-184$.

Gonzalez, R., Bechara, A., Martin, E., 2007. Executive functions among individuals with methamphetamine or alcohol as drugs of choice: preliminary observations. Journal of Clinical and Experimental Neuropsychology 29, 155-159.

Gonzalez, R., Rippeth, J., Carey, C., Heaton, R., Moore, D., Schweinsburg, B., Cherner, M., Grant, I., 2004. Neurocognitive performance of methamphetamine users discordant for history of marijuana exposure. Drug and Alcohol Dependence 76, 181-190.

Grant, S., Contoreggi, C., London, E., 2000. Drug abusers show impaired performance in a laboratory test of decision making. Neuropsychologia 38, 1180-1187.

Graziani, M., Milella, M., Nencini, P., 2008. Khat chewing from the pharmacological point of view: An update. Substance Use \& Misuse 43, 762-783.

Griffiths, R., 1998. Qat use in London: a study of qat use among a sample of Somalis living in London. London, Drugs Prevention Initiative Paper No. 26. Home Office, Central Drugs Prevention Unit. Ref Type: Report.

Harakas, P., Foulds, J., 2002. Acute effects of glucose tablets on craving, withdrawa symptoms, and sustained attention in 12-h abstinent tobacco smokers. Psychopharmacology (Berlin) 161, 271-277.

Harris, D., Batki, S., 2000. Stimulant psychosis: symptom profile and acute clinical course. American Journal on Addictions 9, 28-37.

Hart, C., Ward, A., Haney, M., Foltin, R., Fischman, M., 2001. Methamphetamine selfadministration by humans. Psychopharmacology 157, 75-81.

Hassan, N., Gunaid, A., Abdo-Rabbo, A., Abdel-Kader, Z., al Mansoob, M., Awad, A. Murray-Lyon, I., 2000. The effect of Qat chewing on blood pressure and heart rate in healthy volunteers. Tropical Doctor 30, 107-108.

Hassan, N., Gunaid, A., El Khally, F., Al Noami, M., Murray-Lyon, I., 2005. Khat chewing and arterial blood pressure. A randomized controlled clinical trial of alpha- 1 and selective beta-1 adrenoceptor blockade. Saudi Medical Journal 26, 537-541.

Hoffman, W., Moore, M., Templin, R., McFarland, B., Hitzemann, R., Mitchell, S., 2006 Neuropsychological function and delay discounting in methamphetaminedependent individuals. Psychopharmacology 188, 162-170.

Hom, N., Dolan, M., Elliott, R., Deakin, J., Woodruff, P., 2003. Response inhibition and impulsivity: an MRI study. Neuropsychologia 41, 1959-1966.

Humfleet, G., Haas, A., 2004. Is marijuana use becoming a 'gateway' to nicotine dependence? Addiction 99, 5-6.

Hurt, R., Patten, C., 2003. Treatment of tobacco dependence in alcoholics. Recent Developments in Alcoholism 16, 335-359.

Hutchison, K., Swift, R., 1999. Effect of D-amphetamine on prepulse inhibition of the startle reflex in humans. Psychopharmacology 143, 394-400.

Iwanami, A., Sugiyama, A., Kuroki, N., Toda, S., Kato, N., Nakatani, Y., Horita, N., Kaneko, T., 1994. Patients with methamphetamine psychosis admitted to a psychiatric hospital in Japan. A preliminary report. Acta Psychiatrica Scandinavica 89, 428-432.

John, U., Meyer, C., Rumpf, H., Schumann, A., Thyrian, J., Hapke, U., 2003. Strength of the relationship between tobacco smoking, nicotine dependence and the severity of alcohol dependence syndrome criteria in a population-based sample. Alcohol and Alcoholism 38, 606-612.
Johnson, B., Ait-Daoud, N., Wells, L., 2000. Effects of isradipine, a dihydropyridineclass calcium channel antagonist, on D-methamphetamine-induced cognitive and physiological changes in humans. Neuropsychopharmacology 22, 504-512.

Johnson, B., Roache, J., Ait-Daoud, N., Wallace, C., Wells, L., Wang, Y., 2005. Effects of isradipine on methamphetamine-induced changes in attentional and perceptual-motor skills of cognition. Psychopharmacology 178, 296-302.

Jovanovski, D., Erb, S., Zakzanis, K., 2005. Neurocognitive deficits in cocaine users: a quantitative review of the evidence. Journal of Clinical and Experimental Neuropsychology 27, 189-204.

Kalechstein, A., Newton, T., Green, M., 2003. Methamphetamine dependence is associated with neurocognitive impairment in the initial phases of abstinence. Journal of Neuropsychiatry and Clinical Neurosciences 15, 215-220.

Kalechstein, A., Newton, T., Longshore, D., Anglin, M., van Gorp, W., Gawin, F., 2000. Psychiatric comorbidity of methamphetamine dependence in a forensic sample. Journal of Neuropsychiatry and Clinical Neurosciences 12, 480-484.

Kalix, P., 1996. Catha edulis, a plant that has amphetamine effects. Pharmacy World and Science 18, 69-73.

Kalix, P., 1992. Cathinone, a natural amphetamine. Pharmacology and Toxicology $70,77-86$

Kalix, P., 1994. Khat, an amphetamine-like stimulant. Journal of Psychoactive Drugs 26, 69-74.

Kebede, D, Alem, A., Mitike, G., Enquselassie, F., Berhane, F., Abebe, Y., Ayele, R., Lemma, W., Assefa, T., Gebremichael, T., 2005. Khat and alcohol use and risky sex behaviour among in-school and out-of-school youth in Ethiopia. BMC Public Health 5, 109-117.

Kendler, K., Jacobson, K., Prescott, C., Neale, M., 2003. Specificity of genetic and environmental risk factors for use and abuse/dependence of cannabis, cocaine, hallucinogens, sedatives, stimulants, and opiates in male twins. American Journal of Psychiatry 160, 687-695.

Khalil, N., 1998. Motivators of Yemeni women toward attending qat meetings. Dar Kelmah, Sana'a,Yemen.

Kim, S., Lyoo, I., Hwang, J., Sung, Y., Lee, H., Lee, D., Jeong, D., Renshaw, P., 2005. Frontal glucose hypometabolism in abstinent methamphetamine users. Neuropsychopharmacology 30, 1383-1391.

Kimani, S., Nyongesa, A., 2008. Effects of single daily khat (Catha edulis) extract on spatial learning and memory in CBA mice. Behavioural Brain Research 195, 192-197.

Kimani, S., Patel, N., Kioy, P., 2008. Effect of single and daily khat (Catha edulis) extract on locomotor behaviour in CBA mice. Scientific Research and Essay 3. 187-196.

Koelega, H., 1993. Stimulant drugs and vigilance performance: a review. Psychopharmacology (Berlin) 111, 1-16.

Kreek, M., Bart, G., Lilly, C., LaForge, K., Nielsen, D., 2005b. Pharmacogenetics and human molecular genetics of opiate and cocaine addictions and their treatments. Pharmacology Review 57, 1-26.

Kreek, M., Nielsen, D., Butelman, E., LaForge, K., 2005a. Genetic influences on impulsivity, risk taking, stress responsivity and vulnerability to drug abuse and addiction. Nature Neuroscience 8, 1450-1457.

Lai, S., Lai, H., Page, J., McCoy, C., 2000. The association between cigarette smoking and drug abuse in the United States. Journal of Addictive Diseases 19, 11-24.

Logan, G., 1994. On the ability to inhibit thought and action: a users' guide to the stop signal paradigm. In: Dagenbach, D., Carr, T. (Eds.), Inhibitory Processes in Attention, Memory and Language. Academic Press, San Diego, pp. 189-239.

London, E., Berman, S., Voytek, B., Simon, S., Mandelkern, M., Monterosso, J., Thompson, P., Brody, A., Geaga, J., Hong, M., 2005. Cerebral metabolic dysfunction and impaired vigilance in recently abstinent methamphetamine abusers. Biological Psychiatry 58, 770-778.

McKetin, R., Mattick, R., 1998. Attention and memory in illicit amphetamine users: comparison with non-drug-using controls. Drug and Alcohol Dependence 50, 181-184.

McKetin, R., McLaren, J., Lubman, D., Hides, L., 2006. The prevalence of psychotic symptoms among methamphetamine users. Addiction 101, 1473-1478.

Meredith, C., Jaffe, C., Ang-Lee, K., Saxon, A., 2005. Implications of chronic methamphetamine use: a literature review. Harvard Review of Psychiatry 13, 141-154.

Monterosso, J., Ainslie, G., Xu, J., Cordova, X., Domier, C., London, E., 2006. Frontoparietal cortical activity of methamphetamine-dependent and comparison subjects performing a delay discounting task. Human Brain Mapping 28, 383-393.

Monterosso, J., Aron, A., Cordova, A., Xu, J., London, E., 2005. Deficits in response inhibition associated with chronic methamphetamine abuse. Drug and Alcohol Dependence 79, 273-277.

Moon, M., Do, K., Park, J., Kim, D., 2007. Memory impairment in methamphetamine dependent patients. International Journal of Neuroscience 117, 1-9.

Mumenthaler, M., Taylor, J., O’Hara, R., Yesavage, J., 1998. Influence of nicotine on simulator flight performance in non-smokers. Psychopharmacology (Berlin) $140,38-41$

Munro, C., McCaul, M., Wong, D., Oswald, L., Zhou, Y., Brasic, J., Kuwabara, H., Kumar, A., Alexander, M., Ye, W., 2006. Sex differences in striatal dopamine release in healthy adults. Biological Psychiatry 59, 966-974.

Mwenda, J., Arimi, M., Kyama, M., Langat, D., 2003. Effects of khat (Catha edulis) consumption on reproductive function: a review. East African Medical Journal 80, 318-323.

Nabuzoka, D., Badhadhe, F., 2000. Use and perception of khat among young Somalis in a UK city. Addiction Research 8, 5-26.

Nader, M., Morgan, D., Gage, H., Nader, S., Calhoun, T., Buchheimer, N., Ehrenkaufer, R., Mach, R., 2006. PET imaging of dopamine D2 receptors during chronic cocaine self-administration in monkeys. Nature Neuroscience 9, 1050-1056. 
Nasher, A., Qirbi, A., Ghafoor, M., Catterall, A., Thompson, A., Ramsay, J., Murray-Lyon, I., 1995. Khat chewing and bladder neck dysfunction. A randomized controlled trial of alpha 1-adrenergic blockade. British Journal of Urology 75, 597598.

Nencini, P., Fraioli, S., Pascucci, T., Nucerito, C., 1998. (-)-Norpseudoephedrine, a metabolite of cathinone with amphetamine-like stimulus properties, enhances the analgesic and rate decreasing effects of morphine, but inhibits its discriminative properties. Behavioural Brain Research 92, 11-20.

Newton, T., Kalechstein, A., Duran, S., Vansluis, N., Ling, W., 2004. Methamphetamine abstinence syndrome: preliminary findings. American Journal on Addictions 13, 248-255.

Nordahl, T., Salo, R., Leamon, M., 2003. Neuropsychological effects of chronic methamphetamine use on neurotransmitters and cognition: a review. Journal of Neuropsychiatry and Clinical Neurosciences 15, 317-325.

Numan, N., 2004. Exploration of adverse psychological symptoms in Yemeni khat users by the Symptom Checklist-90 (SCL-90). Addiction 99, 61-65.

Odenwald, M., 2007. Chronic khat use and psychotic disorders: a review of the literature and future prospects. Sucht 53, 9-22.

Odenwald, M., Hinkel, H., Schauer, E., Neuner, F., Schauer, M., Elbert, T., 2007. The consumption of khat and other drugs in Somali combatants: a cross-sectional study. PLoS Medicine 4, 1959-1972.

Odenwald, M., Hinkel, H., Schauer, E., Schauer, M., Elbert, T., Neuner, F., Rockstroh, B., 2009. Use of khat and posttraumatic stress disorder as risk factors for psychotic symptoms: a study of Somali combatants. Social Science \& Medicine 69, 1040-1048.

Odenwald, M., Neuner, F., Schauer, M., Elbert, T., Catani, C., Lingenfelter, B., Hinkel, H., Hafner, H., Rockstroh, B., 2005. Khat use as risk factor for psychotic disorders: a cross-sectional and case-control study in Somalia. BMC Medicine 3, 5-15.

Ornstein, T., Iddon, J., Baldacchino, A., Sahakian, B., London, M., Everitt, B., Robbins, T., 2000. Profiles of cognitive dysfunction in chronic amphetamine and heroin abusers. Neuropsychopharmacology 23, 113-126.

Owen, A., 1997. Cognitive planning in humans: neuropsychological, neuroanatomical and neuropharmacological perspectives. Progress in Neurobiology 53, 431-450.

Owen, A., Sahakian, B., Semple, J., Polkey, C., Robbins, T., 1995. Visuo-spatial shortterm recognition memory and learning after temporal lobe excisions, frontal lobe excisions or amygdalo-hippocampectomy in man. Neuropsychologia 33, $1-24$.

Pantelis, C., Hindler, C., Taylor, J., 1989. Use and abuse of khat (Catha edulis): a review of the distribution, pharmacology, side effects and a description of psychosis attributed to khat chewing. Psychological Medicine 19, 657-668.

Patel, N., 2000. Mechanism of action of cathinone: the active ingredient of khat (Catha edulis). East African Medical Journal 77, 329-332.

Paulus, M., Hozack, N., Zauscher, B., Frank, L., Brown, G., Braff, D., Schuckit, M., 2002. Behavioral and functional neuroimaging evidence for prefrontal dysfunction in methamphetamine-dependent subjects. Neuropsychopharmacology 26, 53-63.

Pehek, E., Schechter, M., 1990. Discriminative stimulus properties of $(+)$ cathine, an alkaloid of the khat plant. Pharmacology Biochemistry and Behavior 36, 267-271.

Pehek, E., Schechter, M., Yamamoto, B., 1990. Effects of cathinone and amphetamine on the neurochemistry of dopamine in vivo. Neuropharmacology 29, 1171-1176.

Perkins, K., Epstein, L., Stiller, R., Sexton, J., Debski, T., Jacob, R., 1990. Behavioral performance effects of nicotine in smokers and nonsmokers. Pharmacology, Biochemistry and Behavior 37, 11-15.

Pirastu, R., Fais, R., Messina, M., Bini, V., Spiga, S., Falconieri, D., Diana, M., 2006. Impaired decision-making in opiate-dependent subjects: effect of pharmacological therapies. Drug and Alcohol Dependence 83, 163-168.

Rippeth, J., Heaton, R., Carey, C., Marcotte, T., Moore, D., Gonzalez, R., Wolfson, T., Grant, I., 2004. Methamphetamine dependence increases risk of neuropsychological impairment in HIV infected persons. Journal of the International Neuropsychological Society 10, 1-14.

Rogers, R., Andrews, T., Grasby, P., Brooks, D., Robbins, T., 2000. Contrasting cortical and subcortical activations produced by attentional-set shifting and reversal learning in humans. Journal of Cognitive Neuroscience 12, 142-162.

Rogers, R., Everitt, B., Baldacchino, A., Blackshaw, A., Swanson, R., Wynne, K., Baker, N., Hunter, J., Carthy, T., Booker, E., London, M., Deakin, J., Sahakian, B., Robbins, T., 1999b. Dissociable deficits in the decision-making cognition of chronic amphetamine abusers, opiate abusers, patients with focal damage to prefrontal cortex, and tryptophan-depleted normal volunteers: evidence for monoaminergic mechanisms. Neuropsychopharmacology 20, 322-339.

Rogers, R., Owen, A., Middleton, H., Williams, E., Pickard, J., Sahakian, B., Robbins, T., 1999a. Choosing between small, likely rewards and large, unlikely rewards activates inferior and orbital prefrontal cortex. Journal of Neuroscience 19, 9029-9038. Salo, R, Nordahl, T., Natsuaki, Y., Leamon, M., Galloway, G., Waters, C., Moore, C.,
Buonocore, M., 2007. Attentional control and brain metabolite levels in methamphetamine abusers. Biological Psychiatry 61, 1272-1280.

Salo, R., Nordahl, T., Possin, K., Leamon, M., Gibson, D., Galloway, G., Flynn, N., Henik, A., Pfefferbaum, A., Sullivan, E., 2001. Reduced cognitive inhibition in methamphetamine-dependent individuals (abstract presented at Society of Neuroscience, San Diego, CA).

Salo, R., Nordahl, T., Possin, K., Leamon, M., Gibson, D., Galloway, G., Flynn, N., Henik, A., Pfefferbaum, A., Sullivan, E., 2002. Preliminary evidence of reduced cognitive inhibition in methamphetamine-dependent individuals. Psychiatry Research $111,65-74$.
Scott, J., Woods, S., Matt, G., Meyer, R., Heaton, R., Atkinson, J., Grant, I., 2007. Neurocognitive effects of methamphetamine: a critical review and meta-analysis. Neuropsychology Review 17, 275-297.

Selassie, S., Gebre, A., 1996. Rapid assessment of drug abuse in Ethiopia. Bulletin on Narcotics 48, 53-63.

Semple, S., Patterson, T., Grant, I., 2003. Binge use of methamphetamine among HIV-positive men who have sex with men: pilot data and HIV prevention implications. AIDS Education and Prevention 15, 133-147.

Semple, S., Patterson, T., Grant, I., 2004. A comparison of injection and non-injection methamphetamine-using HIV positive men who have sex with men. Drug and Alcohol Dependence 76, 203-212.

Semple, S., Zians, J., Grant, I., Patterson, T., 2005. Impulsivity and methamphetamine use. Journal of Substance Abuse Treatment 29, 85-93.

Shoptaw, S., Peck, J., Reback, C., Rotheram-Fuller, E., 2003. Psychiatric and substance dependence comorbidities, sexually transmitted diseases, and risk behaviors among methamphetamine-dependent gay and bisexual men seeking outpatient drug abuse treatment. Journal of Psychoactive Drugs 35 (Suppl. 1), 161-168.

Silber, B, Croft, R., Papafotiou, K., Stough, C., 2006. The acute effects of D-amphetamine and methamphetamine on attention and psychomotor performance. Psychopharmacology (Berlin) 187, 154-169.

Sim, T., Simon, S., Domier, C., Richardson, K., Rawson, R., Ling, W., 2002. Cognitive deficits among methamphetamine users with attention deficit hyperactivity disorder symptomatology. Journal of Addictive Diseases 21, 75-89.

Simon, S., Dacey, J., Glynn, S., Rawson, R., Ling, W., 2004. The effect of relapse on cognition in abstinent methamphetamine abusers. Journal of Substance Abuse Treatment 27, 59-66.

Simon, S., Domier, C., Carnell, J., Brethen, P., Rawson, R., Ling, W., 2000. Cognitive impairment in individuals currently using methamphetamine. American Journal on Addictions 9, 222-231.

Simon, S., Domier, C., Sim, T., Richardson, K., Rawson, R., Ling, W., 2002. Cognitive performance of current methamphetamine and cocaine abusers. Journal of Addictive Diseases 21, 61-74.

Soetens, E., Casaer, S., D’Hooge, R., Hueting, J., 1995. Effect of amphetamine on longterm retention of verbal material. Psychopharmacology 119, 155-162.

Srisurapanont, M., Ali, R., Marsden, J., Sunga, A., Wada, K., Monteiro, M., 2003. Psychotic symptoms in methamphetamine psychotic in-patients. International Journal of Neuropsychopharmacology 6, 347-352.

Stroop, J., 1992. Studies of Interference in Serial Verbal Reactions (Reprinted from Journal Experimental Psychology, vol. 18, pp. 643-662, 1935). Journal of Experimental Psychology-General 121, 15-23.

Swerdlow, N., Geyer, M., 1998. Using an animal model of deficient sensorimotor gating to study the pathophysiology and new treatments of schizophrenia. Schizophrenia Bulletin 24, 285-301.

Thompson, P., Hayashi, K., Simon, S., Geaga, J., Hong, M., Sui, Y., Lee, J., Toga, A., Ling, W., London, E., 2004. Structural abnormalities in the brains of human subjects who use methamphetamine. The Journal of Neuroscience 24, 6028-6036.

Toennes, S., Harder, S., Schramm, M., Niess, C., Kauert, G., 2003. Pharmacokinetics of cathinone, cathine and norephedrine after the chewing of khat leaves. British Journal of Pharmacology 56, 125-130.

Toennes, S., Kauert, G., 2004. Driving under the influence of khat - alkaloid concentrations and observations in forensic cases. Forensic Science International 140, 85-90.

Ujike, H., Sato, M., 2004. Clinical features of sensitization to methamphetamine observed in patients with methamphetamine dependence and psychosis. Annals of the New York Academy of Sciences 1025, 279-287.

Verdejo-Garcia, A., Lawrence, A., Clark, L., 2008. Impulsivity as a vulnerability marker for substance-use disorders: review of findings from high-risk research, problem gamblers and genetic association studies. Neuroscience and Biobehavioral Reviews 32, 777-810.

Verdejo-Garcia, A., Perez-Garcia, M., 2007a. Ecological assessment of executive functions in substance dependent individuals. Drug and Alcohol Dependence 90 48-55.

Verdejo-Garcia, A., Perez-Garcia, M., 2007b. Profile of executive deficits in cocaine and heroin polysubstance users: common and differential effects on separate executive components. Psychopharmacology 190, 517-530.

Volkow, N., Chang, L., Wang, G., Fowler, J., Franceschi, D., Sedler, M., Gatley, S. Miller, E., Hitzemann, R., Ding, Y., Logan, J., 2001b. Loss of dopamine transporters in methamphetamine abusers recovers with protracted abstinence. Journal of Neuroscience 21, 9414-9418.

Volkow, N., Chang, L., Wang, G., Fowler, J., Leonido-Yee, M., Franceschi, D., Sedler, M., Gatley, S., Hitzemann, R., Ding, Y., Logan, J., Wong, C., Miller, E., 2001a. Association of dopamine transporter reduction with psychomotor impairment in methamphetamine abusers. American Journal of Psychiatry 158, 377-382.

Volkow, N., Chang, L., Wang, G., Fowler, J., Franceschi, D., Sedler, M., Gatley, S. Hitzemann, R., Ding, Y., Wong, C., Logan, J., 2001c. Higher cortical and lower subcortical metabolism in detoxified methamphetamine abusers. American Journal of Psychiatry 158, 383-389.

Wang, G., Volkow, N., Chang, L., Miller, E., Sedler, M., Hitzemann, R., Zhu, W., Logan, J., Ma, Y., Fowler, J., 2004. Partial recovery of brain metabolism in methamphetamine abusers after protracted abstinence. American Journal of Psychiatry $161,242-248$.

Warfa, N., Klein, A., Bhui, K., Leavey, G., Craig, T., Stansfeld, S., 2007. Khat use and mental illness: a critical review. Social Science and Medicine 65, 309-318.

Widler, P., Mathys, K., Brenneisen, R., Kalix, P., Fisch, H., 1994. Pharmacodynamics and pharmacokinetics of khat: a controlled study. Clinical Pharmacology \& Therapeutics 55, 556-562. 
Woods, S., Rippeth, J., Conover, E., Gongvatana, A., Gonzalez, R., Carey, C., Cherner, M., Heaton, R., Grant, I., 2005. Deficient strategic control of verbal encoding and retrieval in individuals with methamphetamine dependence. Neuropsychology 19, 35-43.

Yousef, G., Huq, Z., Lambert, T., 1995. Khat chewing as a cause of psychosis. British Journal of Hospital Medicine 54, 322-326.

Yucel, M., Lubman, D., 2007. Neurocognitive and neuroimaging evidence of behavioural dysregulation in human drug addiction: implications for diagnosis, treatment and prevention. Drug and Alcohol Review 26, 33-39.
Yucel, M., Lubman, D., Harrison, B., Fornito, A., Allen, N., Wellard, R., Roffel, K. Clarke, K., Wood, S., Forman, S., Pantelis, C., 2007. A combined spectroscopic and functional MRI investigation of the dorsal anterior cingulated region in opiate addiction. Molecular Psychiatry 12, 691-702.

Zweben, J., Cohen, J., Christian, D., Galloway, G., Salinardi, M., Paret, D., Iguchi, M., 2004. Psychiatric symptoms in methamphetamine users. American Journal on Addictions 13, 181-190. 